Nicholas Leplat, Jozef Federič, Katarína Šulková, Mária Sudolská, Florent Louis, Ivan Černušák, and Michel Jean Rossi*

\title{
The Kinetics of the Reaction
}

$\mathrm{C}_{2} \mathrm{H}_{5}^{*}+\mathrm{HI} \rightarrow \mathrm{C}_{2} \mathrm{H}_{6}+\mathrm{I}^{\circ}$ over an Extended Temperature Range (213-623 K): Experiment and Modeling

DOI 10.1515/zpch-2015-0607

Received March 30, 2015; accepted August 15, 2015

Abstract: The present study reports temperature dependent rate constants $k_{1}$ for the title reaction across the temperature range 213 to $293 \mathrm{~K}$ obtained in a Knudsen flow reactor equipped with an external free radical source based on the reaction $\mathrm{C}_{2} \mathrm{H}_{5} \mathrm{I}+\mathrm{H}^{*} \rightarrow \mathrm{C}_{2} \mathrm{H}_{5}^{*}+\mathrm{HI}$ and single VUV-photon ionization mass spectrometry using Lyman- $\alpha$ radiation of $10.2 \mathrm{eV}$. Combined with previously obtained high-temperature data of $k_{1}$ in the range 298-623 $\mathrm{K}$ using the identical experimental equipment and based on the kinetics of $\mathrm{C}_{2} \mathrm{H}_{5}^{*}$ disappearance with increasing $\mathrm{HI}$ concentration we arrive at the following temperature dependence

*Corresponding author: Michel Jean Rossi, Laboratory of Atmospheric Chemistry (LAC), Paul Scherrer Institute (PSI), CH-5232 Villigen PSI, Switzerland, e-mail: michel.rossi@psi.ch Nicholas Leplat: Laboratory of Atmospheric Chemistry (LAC), Paul Scherrer Institute (PSI), CH-5232 Villigen PSI, Switzerland; and present address: Melbourne School of Engineering, Mechanical Engineering, Engineering Block E Bldg., The University of Melbourne, Parkville 3010 VIC, Australia

Jozef Federič, Ivan Černušák: Department of Physical and Theoretical Chemistry, Faculty of Natural Sciences, Comenius University, Mlynskádolina CH1, 84215, Bratislava, Slovakia Katarína Šulková: Advanced Technologies Research Institute, Faculty of Materials Science and Technology, Slovak University of Technology in Bratislava, Hajdóczyho 1, 91724 Trnava, Slovakia

Mária Sudolská: Department of Physical and Theoretical Chemistry, Faculty of Natural Sciences, Comenius University, Mlynskádolina CH1, 84215, Bratislava, Slovakia; and Regional Centre of Advanced Technologies and Materials, Department of Physical Chemistry, Faculty of Science, Palacký University Olomouc, 17, listopadu 12, 77146 Olomouc, Czech Republic Florent Louis: PhysicoChimie des Processus de Combustion et de l'Atmosphère (PC2A), UMR 8522 CNRS/Lille1, Université Lille 1 Sciences et Technologies, Cité Scientifique, Bât. C11/C5, 59655 Villeneuve d'Ascq Cedex, France 
best described by a three-parameter fit to the combined data set: $k_{1}=(1.89 \pm$ 1.19) $10^{-13}(T / 298)^{2.92 \pm 0.51} \exp ((3570 \pm 1500) / R T), R=8.314 \mathrm{~J} \mathrm{~mol}^{-1} \mathrm{~K}^{-1}$ in the range $213-623 \mathrm{~K}$. The present results confirm the general properties of kinetic data obtained either in static or Knudsen flow reactors and do nothing to reconcile the significant body of data obtained in laminar flow reactors using photolytic free radical generation and suitable free radical precursors. The resulting rate constant for wall-catalyzed disappearance of ethyl radical across the full temperature range is discussed.

Highly correlated $a b$ initio quantum chemistry methods and canonical transition state theory were applied for the reaction energy profiles and rate constants. Geometry optimizations of reactants, products, molecular complexes, and transition states are determined at the CCSD/cc-pVDZ level of theory. Subsequent single-point energy calculations employed the DK-CCSD(T)/ANO-RCC level. Further improvement of electronic energies has been achieved by applying spin-orbit coupling corrections towards full configuration interaction and hindered rotation analysis of vibrational contributions. The resulting theoretical rate constants in the temperature range $213-623 \mathrm{~K}$ lie in the range $10^{-11}-10^{-12} \mathrm{~cm}^{3}$ molecule $\mathrm{s}^{-1} \mathrm{~s}^{-1}$, however experiments and theoretical modelling seem at great odds with each other.

Keywords: Ethyl Free Radical, H-Metathesis, Reaction Rate Constant, Temperature Dependence, Arrhenius Rate Parameters, ab initio Calculations, Potential Energy Surface, Spin-Orbit Interaction.

Dedicated to Prof. Dr. Dr. h.c. mult. Jürgen Troe on the occasion of his $75^{\text {th }}$ birthday

\section{Introduction}

Reactions (R1) and (R2) may be found in textbooks and reviews of chemical kinetics as belonging to a class of elementary reactions, namely atom transfer or metathesis reactions involving atomic hydrogen or halogen whose activation energies were found to have small positive values [1].

$$
\begin{aligned}
& \mathrm{C}_{2} \mathrm{H}_{5}^{\cdot}+\mathrm{HI} \rightarrow \mathrm{C}_{2} \mathrm{H}_{6}+\mathrm{I}^{\cdot} \\
& \mathrm{C}_{2} \mathrm{H}_{5}^{\cdot}+\mathrm{Cl}_{2} \rightarrow \mathrm{C}_{2} \mathrm{H}_{5} \mathrm{Cl}+\mathrm{Cl}^{\cdot}
\end{aligned}
$$

Some time ago, this convenient and simple classification as elementary reaction came into question because experimental work based on laminar flow tube kinetics coupled to photoionization mass spectrometric detection of alkyl free radicals 
and flash-photolysis resonance fluorescence of the resulting product atomic halogen strongly hinted at distinctly different activation parameters for atom transfer reactions [2-4]. In distinct contrast to the classical results these newer experiments yielded small negative activation energies. Together with the measured pre-exponential factors these more recent experiments resulted in large rate constants associated with a negative temperature dependence, in strong contrast to the small rate constants associated with a positive temperature dependence. Far from settled, the scientific community continues the search for a scientific reconciliation of this disagreement: the dividing line or discriminating difference between both groups of experiments seems to be that the newer results are all associated with UV (excimer laser) photolytic generation of free radicals using a suitable molecular precursor whereas the older results made use of thermal methods of free radical generation. The proponents of the negative activation energy/high value of the rate constant have performed a select few experiments at total pressures up to tens of Torr of $\mathrm{He}$ or $\mathrm{N}_{2}$ that should have relaxed and thermalized the alkyl free radical after UV photolysis before Reaction (R1) or (R2) could have taken place. Needless to say that these high-pressure experiments also resulted in high values of the rate constant associated with a negative temperature dependence $[4,5]$. However, there are exceptions to the rule where newer results obtained in laminar flow tubes connected to photolytic free radical generation have led to low rate constants coupled to positive temperature dependence for no obvious reasons. Examples are the free radicals $\mathrm{C}_{3} \mathrm{H}_{5}^{*}$ (allyl), $\mathrm{CF}_{2} \mathrm{Cl}^{\circ}, \mathrm{CF}_{3}^{\circ}, \mathrm{C}_{3} \mathrm{H}_{3}^{*}$ (propargyl) and $\mathrm{CFCl}_{2}^{\circ}$ in their reaction with $\mathrm{Cl}_{2}$ analogous to Reaction (R2) $[6,7]$.

In addition, recent $a b$ initio quantum chemical work on reactions like (R1) using the bromine analog have been found to be consistent with a negative activation energy over a fairly large temperature range, albeit at the exclusion of close numerical agreement [8] with published experimental results. In order to achieve agreement with the more recent high values of the rate constant such as $k_{1}$ or $k_{2}$ the potential well corresponding to the molecular adduct $\mathrm{C}_{2} \mathrm{H}_{5}^{\bullet} \bullet \bullet \mathrm{HBr}$ had to be arbitrarily adjusted from $\Delta_{\mathrm{r}} H_{0 \mathrm{~K}}^{0}=-9.7$ to $-5.5 \mathrm{~kJ} \mathrm{~mol}^{-1}$ relative to $\mathrm{C}_{2} \mathrm{H}_{5}^{\cdot}+\mathrm{HBr}$ where the former value resulted from the quantum chemical search of the optimum reaction path. So far, sophisticated quantum chemical electronic structure calculations involving heavy iodine atoms in a hydrogen transfer reaction such as (R1) have only been performed for $\mathrm{CH}_{3}^{*}+\mathrm{HI}$ to date [9], so that the work displayed here represents the first example for $\mathrm{C}_{2} \mathrm{H}_{5}^{*}$. The reader is referred to Leplat et al. for a more detailed account of additional background for Reaction (R1) [10], which presents an experimental measurement of $k_{1}$ that is approximately a factor of 20 lower at $300 \mathrm{~K}$ compared to the results of Seetula et al. [11]. So far, sophisticated $a b$ initio electronic structure calculations coupled to chemical-kinetic activation mechanisms have not been able to clearly distinguish between the two sets 
of results for hydrogen metathesis reactions that differ by factors of 20 and more for more complex alkyl free radicals $[10,12,13]$. We hope that future, hopefully imminent, developments will allow a quantitative evaluation of the two sets of results on the level of sophisticated $a b$ initio electronic structure theory coupled to detailed chemical kinetic models.

In this work we have extended the temperature range of Reaction (R1) from ambient down to $213 \mathrm{~K}$ in order to confirm the temperature dependence obtained in previous work [10]. The emphasis of the present work is put on the kinetics of Reaction (R1), namely the reaction rate parameters (pre-exponential factor $A$, activation energy $E_{\mathrm{a}}$ ), rather than the thermochemistry of ethyl free radical. It must be stated that the thermochemistry of ethyl was never really at the center of interest and did not constitute a point of contention for H-metathesis (transfer) reactions. This also becomes apparent when comparing the previously recommended results with the new measurements $[10,12,14]$. This is entirely understandable when one considers the used "strategy" based on the "Third Law" procedure: we compute the equilibrium constant at high temperature (600-700 K) by taking the ratio of the (measured) forward and (published) reverse rate constant and evaluate the thermo-chemical parameters at high temperature which subsequently are scaled down to $298 \mathrm{~K}$. The reason for this apparent lack of sensitivity of the thermo-chemical parameters is the fact that both groups of disparate measurements of Reaction (R1), namely high ([11]) and low ([10, 12]) values, practically coincide at high temperature which leads to similar or even essentially identical equilibrium constants at high temperature. The present work is based on the validation work on ethyl free radical published by Leplat et al. in [10] such that typical validation experiments have not been repeated in the present work, namely the investigation of the reaction kinetics as a function of wall coating of the reaction vessel, the source of free radicals in the external radical source and mass balance considerations. As a disclaimer we would like to stress that the present work is based on the measurement of the disappearance of ethyl free radicals using the dedicated SPIMS experiment [14] in contrast to the Closed Shell Product (CSP) detection presented in [10].

\section{Experimental and theoretical procedures}

The experimental technique used for the measurement of $k_{1}$ (Reaction R1) closely follows our published procedure [10] using a dedicated instrument [14] based on single VUV photoionization mass spectrometric (SPIMS) detection of ethyl free radical. Both of these publications present a sketch of the experimental appara- 
Table 1: Important parameters of the used Knudsen flow reactors "a" and "c".

\begin{tabular}{lrr}
\hline & Reactor a & Reactor c \\
\hline Volume $\left(\mathrm{cm}^{3}\right)$ & 213 & 272.6 \\
Internal area $\left(\mathrm{cm}^{2}\right)$ & 256 & 253 \\
$\Phi$ exit aperture $(\mathrm{mm})$ & 3.5 & 2.0 \\
$k_{e}\left(\mathrm{~s}^{-1}\right)$ & $1.034 \times(T / M)^{1 / 2}$ & $0.441 \times(T / M)^{1 / 2}$ \\
$k_{e}\left(\mathrm{~s}^{-1}\right)^{\mathrm{a}}$ & $1.649 \times(T / M)^{1 / 2}$ a & $0.420 \times(T / M)^{1 / 2}$ a \\
$\omega\left(\mathrm{s}^{-1}\right)$ & $4386 \times(T / M)^{1 / 2}$ & $3388 \times(T / M)^{1 / 2}$ \\
\hline
\end{tabular}

a Calculated on the basis of nominal values $(3.5$ and $2.0 \mathrm{~mm}$ diameter, respectively).

tus. Briefly, ethyl free radical was generated upstream of the Knudsen flow reactor using Reactions (R3) and (R4). The microwave discharge $(2.45 \mathrm{GHz})$ was set to $40-60 \mathrm{~W}$ power deposition in the tube leading to approximately

$$
\begin{aligned}
& \mathrm{H}_{2}((\mu) \text {-wave }) \rightarrow 2 \mathrm{H}^{\bullet} \\
& \mathrm{H}^{\cdot}+\mathrm{C}_{2} \mathrm{H}_{5} \mathrm{I} \rightarrow \mathrm{C}_{2} \mathrm{H}_{5}^{\cdot}+\mathrm{HI}\left(\Delta_{\mathrm{r}} H_{0 \mathrm{~K}}^{0}=-74.9 \mathrm{~kJ} \mathrm{~mol}^{-1}\right)
\end{aligned}
$$

$50 \%$ destruction of $\mathrm{H}_{2}$ in a $20 \% \mathrm{H}_{2}$ in Ar mixture. Ar has been used as an internal standard for MS detection of ethyl free radical and stable species. The total pressure in the discharge and the downstream free radical mixing tube was in the range 0.1 to $0.3 \mathrm{mbar}$. The reactive flow containing ethyl free radical was subsequently admitted to the Knudsen flow reactor across a $1-2 \mathrm{~cm}$ long and 1-2 mm ID PTFE capillary. Two Knudsen flow reactors of different residence times have been used, namely reactors "a" and "c", where the former has been used in the past in the framework of technique validation and collection of kinetic data at higher temperatures [10]. Reactor "c" was designed in order to adapt the reaction vessel to slower kinetics, thus longer gas residence time that was expected with decreasing temperature. The reactant hydrogen iodide is admitted to the reaction vessel by means of a second capillary inlet line and interacts with ethyl free radical for the first time inside the Knudsen flow reactor without prior interaction. Characteristic parameters of both FEP-coated Knudsen flow reactors are given in Table 1. Experiments have been performed at different temperatures in the range 213-293 K thanks to a cooling unit (HAAKE Phoenix II P2-CT90W) with an external pump, through which the cooling fluid ethanol was pumped through PVC tubing wound around the insulated body of the reaction vessel. The temperature was monitored by two type $\mathrm{K}$ thermocouple elements whose readings agreed to within $\pm 2 \mathrm{~K}$. The calibration of the escape rate constants for both reaction vessels has been described in detail before [10]. In order to determine the two unknown 
rate constants of the present reaction system, namely $k_{1}$ and $k_{w}^{\mathrm{C}_{2} \mathrm{H}_{5}}$, we need to collect two linearly independent data sets which is the reason for the use of two reaction vessels of significantly differing geometry or gas residence times.

VUV-photons were obtained by discharging pure $\mathrm{H}_{2}$ in order to obtain essentially pure Lyman- $\alpha$ radiation at $121.5 \mathrm{~nm}(10.2 \mathrm{eV})$ as a source of photoionization of molecular species. Previously we had varied numerous experimental parameters such as the ethyl free radical precursor $\left(\mathrm{C}_{2} \mathrm{H}_{5} \mathrm{I}, \mathrm{C}_{2} \mathrm{H}_{6}\right)$ and corresponding reaction (I vs. $\mathrm{Cl}$ abstraction) leading to the generation of thermal ethyl free radicals, reaction vessel coating (Halocarbon wax 15-00, FEP (Fluorinated Ethylene Propylene polymer) coating), VUV photolysis frequency $\left(\mathrm{H}_{2} \mathrm{vs} . \mathrm{Cl}_{2}\right.$ discharge lamp), mass balance and data treatment (decay of ethyl free radical vs. observation of closed shell products from Reaction (R1), recombination and disproportionation of ethyl radical) to find out that the obtained rate constant of interest $\left(k_{1}\right)$ was invariant to all these changes. Therefore, we decided to forego the validation of the method and selected a unique set of conditions described above.

The used gases and liquids were provided by Messer ( $\mathrm{Ar} \geq 99.998 \%$, $\left.\mathrm{H}_{2} \geq 99.995 \%\right)$ and Sigma Aldrich $\left(\mathrm{C}_{2} \mathrm{H}_{5} \mathrm{I} \geq 99 \%\right)$. The HI was prepared according to the procedure described by Dillon and Young [15]. Both condensable gases (HI and $\mathrm{C}_{2} \mathrm{H}_{5} \mathrm{I}$ ) were purified and degassed by using several freeze (77.36 K)-pumpthaw cycles. The HI was stored in a glass bulb which was painted black in order to minimize photolytic decomposition into $\mathrm{I}_{2}$ and $\mathrm{H}_{2}$.

Geometry parameters for reactants $\left(\mathrm{HI}\right.$ and ${ }^{\circ} \mathrm{C}_{2} \mathrm{H}_{5}$ ), products ( ${ }^{\circ} \mathrm{I}$ and $\mathrm{C}_{2} \mathrm{H}_{6}$ ), and intermediate species (transition state (TS) and molecular complexes in the forward (MCR) and reverse (MCP) directions) were optimized with the coupled cluster method using both single and double substitutions (CCSD) [16-19], Dunning's double- $\zeta$ correlation consistent basis set cc-pVDZ for $\mathrm{H}$ and $\mathrm{C}$ atoms [20] and Peterson's pseudo potential basis set of the same class on iodine [21]. Vibrational frequencies were calculated numerically at the same level as the one used for geometry optimizations using the rigid rotor-harmonic oscillator (RRHO) approximation. Vibrational frequencies and zero-point energy corrections have been scaled by 0.947 [22] to compensate for the errors arising from the anharmonic character of vibrational modes and the approximate electronic structure description. Intrinsic Reaction Coordinate (IRC) calculations have been performed using the algorithm [23, 24] available in the GAUSSIAN program [25].

The low frequency vibrational modes corresponding to hindered (internal) rotations may cause substantial errors in the calculations of molecular partition functions and thermodynamic properties when treated in the standard rigid rotor-harmonic oscillator (RRHO) approximation [26]. Therefore, we adopted a simple one-dimensional (1D) hindered rotor model developed by Pfaendtner et al. [27] as implemented in the code Calctherm [28]. In this approach, the one 
dimensional Schrödinger equation is solved for each internal rotation, giving the energy levels to compute corresponding partition functions and, finally, enabling one to obtain the correct thermodynamic properties. The whole procedure consists of 1) calculation of the hindrance potential of a particular internal rotation, 2) the energy potential fit to a Fourier series expansion, 3) calculation of the reduced moment of inertia, and 4) solving the above-mentioned Schrödinger equation. In this work, the rigid scans of potential energy profiles corresponding to internal rotations in the ${ }^{\circ} \mathrm{C}_{2} \mathrm{H}_{5}$, MCR, TS, MCP, and $\mathrm{C}_{2} \mathrm{H}_{6}$ structures were calculated at the CCSD level in combination with cc-pVDZ basis set on all atoms (in the case of iodine, the pseudopotential basis set of the same quality was used). The scanning variable - dihedral angle - has been incremented by $10^{\circ}$ in each step.

For all structures, we have identified as internal rotations the rotations of the $\mathrm{CH}_{3}$ and $\mathrm{CH}_{2}$ groups, respectively, about the $\mathrm{C}-\mathrm{C}$ single bond. The frequencies of the vibrational modes (at CCSD/cc-pVDZ, without scaling) treated as internal rotations are $151 \mathrm{~cm}^{-1}\left(\mathrm{C}_{2} \mathrm{H}_{5}\right), 199 \mathrm{~cm}^{-1}$ (MCR), $306 \mathrm{~cm}^{-1}$ (TS), $330 \mathrm{~cm}^{-1}$ (MCP), and $326 \mathrm{~cm}^{-1}\left(\mathrm{C}_{2} \mathrm{H}_{6}\right)$. The height of energy barrier increases from ${ }^{\circ} \mathrm{C}_{2} \mathrm{H}_{5}$ $\left(2.4 \mathrm{~kJ} \mathrm{~mol}^{-1}\right)$ to MCR $\left(4.1 \mathrm{~kJ} \mathrm{~mol}^{-1}\right)$, TS $\left(6.2 \mathrm{~kJ} \mathrm{~mol}^{-1}\right)$ and MCP $\left(13.5 \mathrm{~kJ} \mathrm{~mol}^{-1}\right)$, and subsequently increases slightly upon formation of the final product $\mathrm{C}_{2} \mathrm{H}_{6}$ $\left(13.7 \mathrm{~kJ} \mathrm{~mol}^{-1}\right)$. The calculated internal rotation barrier in $\mathrm{C}_{2} \mathrm{H}_{6}$ is slightly higher than the experimental value $\left(12.0 \pm 0.5 \mathrm{~kJ} \mathrm{~mol}^{-1}\right)$ [29]. Regarding the symmetry of rotation, the symmetry number 3 could be unambiguously attributed only to the internal rotation of $\mathrm{CH}_{3}$ about $\mathrm{C}-\mathrm{C}$ in the $\mathrm{C}_{2} \mathrm{H}_{6}$ molecule. In the case of the other structures, the $\mathrm{CH}_{3}$ rotating top was considered as asymmetric (symmetry number of 1) owing to the presence of the iodine atom in the corresponding systems (i.e. the three $\mathrm{C}-\mathrm{H}$ bonds in $\mathrm{CH}_{3}$ are not equivalent in MCR, TS, and MCP) and their overall point group symmetry $\left(C_{1}\right)$. The $\mathrm{CH}_{2}$ group is asymmetric with respect to the rotation about the $\mathrm{C}-\mathrm{C}$ bond in the ${ }^{\circ} \mathrm{C}_{2} \mathrm{H}_{5}$ structure (symmetry number 1) because the two $\mathrm{H}$ atoms in $\mathrm{CH}_{2}$ and both $\mathrm{C}$ atoms in the ethyl free radical are not lying in a common plane.

Single-point energy calculations have been performed employing the singlereference coupled-cluster theory including single, double, and non-iterative triple substitutions (CCSD(T)) as implemented in the MOLCAS7 program [30]. Scalar relativistic effects were incorporated using one-component second-order DouglasKroll-Hess approach (DK-CCSD(T)). When calculating the triple-excitation contribution for open-shell species we have used the spin-adaptation procedure of the $T_{2}$ excitation DDVV amplitudes. Relativistic ANO basis sets (ANO-RCC) were used with the large contractions: $\mathrm{H}$ [6s4p3d1f], C[8s7p4d3f2g], and I[10s9p8d5f3g] [31]. The semi-core correlation of the $4 \mathrm{~d}$ electrons on iodine is automatically included when using ANO-RCC sets in MOLCAS. In order to judge the quality of the singlereference $\operatorname{CCSD}(\mathrm{T})$ approach we have carefully monitored the absolute values of 
the $T_{1}$ and $T_{2}$ excitation amplitudes. In all species they were well below 0.1 . This is a fairly safe threshold for the evaluation of the applicability of the single-reference approach in coupled cluster theory and was thoroughly analyzed by Urban and coworkers [32, 33].

The effects of higher excitations on the coupled cluster energies have also been evaluated using the continued fraction approximation (cf) as proposed by Goodson [34]. This method works quite well even for stretched bonds typical for TS, and is applicable for molecules with smooth convergence in CCSD.

The inclusion of the spin-orbit (SO) correction is important for studying the energetics of iodine-containing species [9, 35-39]. The $\mathrm{SO}$ effects have been calculated as described in our previous studies [9, 35, 37-39] using the restricted active space state interaction method (CASSCF/CASPT2/RASSI-SO [40], shortly CASPT2/RASSI-SO), employing the complete active space (CASSCF) wave function as a reference and using the correlation energy contributions from multistate second-order multi-configurational perturbation theory (CASPT2) [41]. Our SO corrections are $-1.7,-2.1$, and $-27.0 \mathrm{~kJ} \mathrm{~mol}^{-1}$ for MCR, TS, and MCP, respectively, while the values for $I$ atom and $\mathrm{HI}$ were -30.0 and $-2.3 \mathrm{~kJ} \mathrm{~mol}^{-1}$ as calculated in our previous work for the reaction of $\mathrm{HI}$ with $\mathrm{CH}_{3}$ radical [9]. It is worth noting that the SO corrections for MCR and MCP are close to the ones obtained for reactants and products with differences amounting to less than $3 \mathrm{~kJ} \mathrm{~mol}^{-1}$. In response to a referee comment we also tested the geometry dependence of the SO corrections. This dependence could be significant for HI or for MCR and TS, both may be regarded as $\mathrm{HI}$ perturbed in the presence of ${ }^{\circ} \mathrm{C}_{2} \mathrm{H}_{5}$ radical. We calculated the potential energy curves for $\mathrm{HI}$ around the minimum both for spin-free and SO-corrected CASPT2 energies. HI is a good test because its SO correction of $2.28 \mathrm{~kJ} \mathrm{~mol}^{-1}$ is important when going towards TS. The plot of the HI energy relative to its SO-corrected minimum in the range 1.4-2.1 Å is displayed in Figure S1 of the Supporting Information. The geometry effect is marginal around the minimum and starts to rise only slightly for the stretched bond, as the free atom character of ${ }^{\circ} \mathrm{I}$ atom becomes more important. MCP mainly consists of iodine atom that is slightly perturbed by the presence of $\mathrm{C}_{2} \mathrm{H}_{6}$ being a weakly bound complex of the type "closed-shell" interacting with an atom, so its effect on the $\mathrm{SO}$ correction on atomic iodine is also marginal. The test showed that the geometry effect on the SO correction does not play a significant role for the reaction at hand.

Although we were using fairly large basis sets for single point energies, it was useful to at least estimate the so-called basis set superposition error (BSSE). BSSE has been calculated using the modification of the original Boys-Bernardi [42, 43] counterpoise (CP) correction as proposed by Xantheas [44]. This modification takes into account the geometry relaxation when going from the subsystems to the supersystem. The CP correction is only applicable to weakly bound molecular 
complexes but not to the transition state, where it can lead to discontinuous potential surfaces [45]. The $\mathrm{CP}$ correction estimated in this way represents the magnitude of the error bars for reaction barriers.

The rate constant $k_{1}$ for the reaction between $\mathrm{HI}$ and $\mathrm{C}_{2} \mathrm{H}_{5}$ involves a hydrogen-bonded adduct in the forward and reverse directions. It was initially analyzed according to the scheme advocated by Singleton and Cvetanoviç [46] for pre-reactive complexes and has been already detailed elsewhere for the $\mathrm{HI}+\mathrm{CH}_{3}^{*}$ reaction [9]. The molecular adducts or complexes are called MCR and MCP depending on whether these adducts are closer to the reactants (entrance channel) or products (exit channel) and are sometimes called inner or outer complexes depending on the direction of reaction.

In this work, the rate constant has been calculated using two different mechanisms:

- direct mechanism:

$$
\mathrm{HI}+\mathrm{C}_{2} \mathrm{H}_{5}^{\bullet} \rightarrow \mathrm{TS} \rightarrow I^{\bullet}+\mathrm{C}_{2} \mathrm{H}_{6}
$$

- complex mechanism:

$$
\begin{aligned}
& \mathrm{HI}+\mathrm{C}_{2} \mathrm{H}_{5}^{\cdot} \stackrel{k_{\mathrm{a}}}{\longrightarrow} \mathrm{MCR} \\
& \mathrm{MCR} \stackrel{k_{\mathrm{b}}}{\longrightarrow} \mathrm{HI}+\mathrm{C}_{2} \mathrm{H}_{5}^{\cdot} \\
& \mathrm{MCR} \stackrel{k_{\mathrm{c}}}{\longrightarrow} \mathrm{TS}
\end{aligned}
$$

For the direct mechanism, the rate constant $k_{1}(T)$ is calculated using the classical transition state theory (TST) [47-49] as:

$$
k(T)=\Gamma(T) \times \frac{k_{\mathrm{B}} T}{h} \times \frac{\mathrm{Q}_{\mathrm{TS}}(T)}{\mathrm{Q}_{\mathrm{R}}(T)} \times \exp \left(-\frac{E_{\mathrm{TS}}-E_{\mathrm{R}}}{k_{\mathrm{B}} T}\right)
$$

For the complex mechanism, the rate constant $k_{1}(T)$ may be obtained from the following equation:

$$
k_{1}(T)=K_{1 \mathrm{a}, 1 \mathrm{~b}}(T) k_{1 \mathrm{c}}(T)
$$

where $K_{1 \mathrm{a}, 1 \mathrm{~b}}$ is the equilibrium constant between MCR and the reactants taking into account Reactions (R1a) and (R1b), and $k_{1 \mathrm{c}}$ is the rate constant for Reaction (R1c). The application of basic statistical thermodynamic principles for the calculation of $K_{1 \mathrm{a}, 1 \mathrm{~b}}=k_{1 \mathrm{a}} / k_{1 \mathrm{~b}}$ and the TST formula to calculate $k_{1 \mathrm{c}}$ leads to the following equations:

$$
K_{1 \mathrm{a}, 1 \mathrm{~b}}(T)=\frac{Q_{\mathrm{MCR}}(T)}{Q_{\mathrm{R}}(T)} \exp \left(\frac{E_{\mathrm{R}}-E_{\mathrm{MCR}}}{k_{\mathrm{B}} T}\right)
$$




$$
k_{1 \mathrm{c}}(T)=\Gamma(T) \times \frac{k_{\mathrm{B}} T}{h} \times \frac{Q_{\mathrm{TS}}(T)}{\mathrm{Q}_{\mathrm{MCR}}(T)} \times \exp \left(-\frac{E_{\mathrm{TS}}-E_{\mathrm{MCR}}}{k_{\mathrm{B}} T}\right)
$$

In above equations, $Q_{\mathrm{R}}(T), \mathrm{Q}_{\mathrm{MCR}}(T)$ and $\mathrm{Q}_{\mathrm{TS}}(T)$ correspond to the total partition functions of the reactants, the pre-reactive complex MCR, and the TS at temperature $T$, respectively, while $E_{\mathrm{R}}, E_{\mathrm{MCR}}$, and $E_{\mathrm{TS}}$ are the total energies at $0 \mathrm{~K}$ including the zero-point energy corrections. $\Gamma(T)$ indicates the transmission coefficient used for the tunneling correction at temperature $T ; k_{\mathrm{B}}$ and $h$ are the Boltzmann and Planck constants, respectively.

The tunneling correction was calculated assuming an unsymmetrical onedimensional Eckart function barrier [50]. This method approximates the potential as a one-dimensional function that is fitted to reproduce the zero-point energy corrected barrier, the enthalpy of reaction at $0 \mathrm{~K}$, and the curvature of the potential at the transition state. In the case of the reaction of $\mathrm{HI}$ with ${ }^{\circ} \mathrm{C}_{2} \mathrm{H}_{5}$, the tunneling corrections are negligible over the studied temperature range $(\Gamma(T)=1.00)$. The GPOP program [51] was used to extract information from Gaussian output files, to estimate the Eckart tunneling corrections, and to perform the rate constant calculations over the temperature range of interest.

\section{Results and discussion}

The significant elementary processes are represented by Reaction (R1) and the following three reactions (R5 to R7):

$$
\begin{array}{ll}
\mathrm{C}_{2} \mathrm{H}_{5}^{\cdot} \rightarrow \text { wall loss and escape }\left(k_{w}^{\mathrm{C}_{2} \mathrm{H}_{5}}, k_{e}^{\mathrm{C}_{2} \mathrm{H}_{5}}\right) & \\
\mathrm{C}_{2} \mathrm{H}_{5}^{\cdot}+\mathrm{C}_{2} \mathrm{H}_{5}^{\cdot} \rightarrow \mathrm{C}_{2} \mathrm{H}_{4}+\mathrm{C}_{2} \mathrm{H}_{6} & \left(k_{d}\right) \\
\mathrm{C}_{2} \mathrm{H}_{5}^{\cdot}+\mathrm{C}_{2} \mathrm{H}_{5}^{\cdot} \rightarrow n-\mathrm{C}_{4} \mathrm{H}_{10} & \left(k_{r}\right)
\end{array}
$$

We shown before that these four reactions represent the complete set of elementary reactions under the chosen experimental conditions of molecular flow in the Knudsen flow reactor in the range 293 to $623 \mathrm{~K}$ [10], which is also valid for t-butyl free radical $\left(\mathrm{t}-\mathrm{C}_{4} \mathrm{H}_{9}^{\circ}\right)$ [12]. It turns out that this also holds for ethyl free radical for the present low temperature range $(213-293 \mathrm{~K})$ as no significant reaction paths other than those given above have been discovered.

In analogy to Leplat, Wokaun and Rossi [10] the analysis of the present reaction system makes use of the flow balance displayed in Equation (5) after establishment of steady-state conditions in the Knudsen flow reactor:

$$
\frac{d\left[\mathrm{C}_{2} \mathrm{H}_{5}\right]}{d t}=R_{\mathrm{C}_{2} \mathrm{H}_{5}}^{\text {in }}-k_{1}\left[\mathrm{C}_{2} \mathrm{H}_{5}\right][\mathrm{HI}]-2\left(k_{r}+k_{d}\right)\left[\mathrm{C}_{2} \mathrm{H}_{5}\right]^{2}
$$




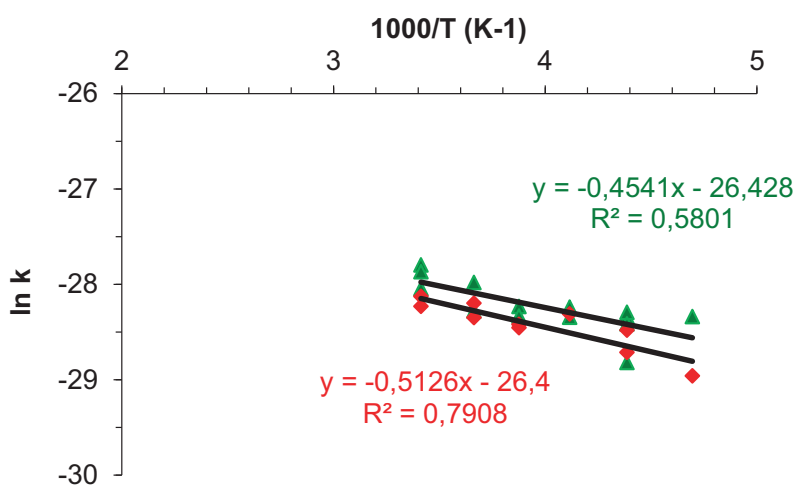

Figure 1: Comparison between results obtained in reactor "a" $(\boldsymbol{\Lambda})$ and " $\mathrm{c}$ " $(\$)$ without accounting for $k_{w}$. The corresponding least-squares Arrhenius lines are displayed. For reactor "a" two points at $295 \mathrm{~K}$ from a previous publication (Table 6 in [10]) have been included in order to decrease the uncertainty in the rate parameters.

$$
-\left(k_{w}^{\mathrm{C}_{2} \mathrm{H}_{5}}+k_{e}^{\mathrm{C}_{2} \mathrm{H}_{5}}\right)\left[\mathrm{C}_{2} \mathrm{H}_{5}\right] \equiv 0
$$

As discussed before [10] the ratio $\frac{I_{\mathrm{C}_{2} \mathrm{H}_{5}}^{0}}{I_{\mathrm{C}_{2} \mathrm{H}_{5}}}$ of the MS signals for ethyl free radical in the absence and presence of $\mathrm{HI}$, respectively, is given in close approximation by Equation (6) as a function of the HI concentration:

$$
\frac{I_{\mathrm{C}_{2} \mathrm{H}_{5}}^{0}}{I_{\mathrm{C}_{2} \mathrm{H}_{5}}}=1+\frac{k_{1}}{k_{w}^{\mathrm{C}_{2} \mathrm{H}_{5}}+k_{e}^{\mathrm{C}_{2} \mathrm{H}_{5}}}[\mathrm{HI}]
$$

The slope of the ratio $\frac{I_{\mathrm{C}_{2} \mathrm{H}_{5}}^{0}}{I_{\mathrm{C}_{2} \mathrm{H}_{5}}}$ as a function of [HI] corresponds to $\frac{k_{1}}{k_{w}^{\mathrm{C}_{2} \mathrm{H}_{5}}+k_{e}^{\mathrm{C}_{2} \mathrm{H}_{5}}}$ where both $k_{1}$ and $k_{w}^{\mathrm{C}_{2} \mathrm{H}_{5}}$ (see Table 2) are unknown in contrast to the escape rate constant $k_{e}^{\mathrm{C}_{2} \mathrm{H}_{5}}$ that has been measured for both reaction vessels "a" and "c" (see above). We need to point out that we routinely observed the recombination product $n-\mathrm{C}_{4} \mathrm{H}_{10}$ in reactor " $\mathrm{c}$ " at all chosen flow rates whereas for reactor "a" the observation of n-butane was possible only at the highest flow rates owing to the smaller gas residence time. This is synonymous with a smaller partial pressure of ethyl free radical leading to a smaller rate of recombination/disproportionation. In contrast, Benson and coworkers were unable to observe n-butane from ethyl free radical recombination in a Knudsen flow reactor at concentrations similar to the present work [52]. The reason for this still represents a mystery, all the more so as the used mass spectrometer is identical to the presently used one (Balzers QMG421, QMA400 analyzer).

Figure 1 displays the rate constants as an Arrhenius plot where the green and red points correspond to results obtained using reactor "a" and "c" by setting 
$k_{w}^{\mathrm{C}_{2} \mathrm{H}_{5}}=0 \mathrm{~s}^{-1}$. The results obtained using both reaction vessels are quite similar across the temperature range $213-293 \mathrm{~K}$ which translates into similar Arrhenius expressions given in Figure 1. In order to obtain higher quality rate parameters based on an Arrhenius plot we have included in Figure 1 two additional points from a previous publication using Reaction (R1) and the identical reactor ("a”) as well as reaction conditions (see Table 6 in ref. [10]). There are 14 points displayed in Figure 1 for reactor "a” (green triangles) whereas Table 3 only lists 12 points newly obtained in the present work. The remaining Figures display all points obtained using reactors "a”, "b" and “c” from present and previous work [10]. Analogous to previous, but recent work on Reaction (R1) reported by Leplat [10] we conclude that $k_{w}^{\mathrm{C}_{2} \mathrm{H}_{5}}$ must be small relative to $k_{e}^{\mathrm{C}_{2} \mathrm{H}_{5}}$. We decided to take into account $k_{w}^{\mathrm{C}_{2} \mathrm{H}_{5}}$ in the evaluation of $k_{1}$ in order to clearly separate both rate constants and obtain a unique value of both $k_{1}$ and $k_{w}^{\mathrm{C}_{2} \mathrm{H}_{5}}$ for the existing data obtained in both reaction vessels. We first establish the individual slopes $S^{a}$ and $S^{c}$ given in Equation (7) by taking the averaged values for the rate constants from the two corresponding Arrhenius expressions displayed in Figure 1. From the ratio $\frac{I_{\mathrm{C}_{2} \mathrm{H}_{5}}^{0}}{I_{\mathrm{C}_{2} \mathrm{H}_{5}}}$ as a function of HI concentration for reaction vessels "a" and " $c$ " we obtain the individual slopes of the straight Arrhenius lines as follows:

$$
S^{a}=k_{1}^{a} / k_{e}^{\mathrm{C}_{2} \mathrm{H}_{5}, a} \text { and } S^{c}=k_{1}^{c} / k_{e}^{\mathrm{C}_{2} \mathrm{H}_{5}, c}
$$

where superscripts " $a$ " and "c" refer to data pertaining to reaction vessels "a" and "c". The goal therefore is to obtain values of $k_{1}$ and $k_{w}^{\mathrm{C}_{2} \mathrm{H}_{5}}$ that are independent of the reaction vessels used in the determination of the kinetics. This is achieved algebraically by applying Equations (8) and (9), which will yield the desired values of $k_{1}$ and $k_{w}^{\mathrm{C}_{2} \mathrm{H}_{5}}$ given the "local" values of $k_{1}\left(k_{1}^{a}, k_{1}^{c}\right)$ and $k_{e}^{\mathrm{C}_{2} \mathrm{H}_{5}}\left(k_{e}^{\mathrm{C}_{2} \mathrm{H}_{5}, a}, k_{e}^{\mathrm{C}_{2} \mathrm{H}_{5}, c}\right)$ for the two reaction vessels "a" and "c".

$$
\begin{aligned}
& k_{1}=\frac{S^{a} S^{c}}{S^{a}-S^{c}}\left(k_{e}^{\mathrm{C}_{2} \mathrm{H}_{5}, c}-k_{e}^{\mathrm{C}_{2} \mathrm{H}_{5}, a}\right) \\
& k_{w}^{\mathrm{C}_{2} \mathrm{H}_{5}}=\frac{S^{c} k_{e}^{\mathrm{C}_{2} \mathrm{H}_{5}, c}-S^{a} k_{e}^{\mathrm{C}_{2} \mathrm{H}_{5}, a}}{S^{a}-S^{c}}
\end{aligned}
$$

Table 2 displays the values of $k_{w}^{\mathrm{C}_{2} \mathrm{H}_{5}}$ at four temperatures, and Figure 2 presents an Arrhenius plot with the current data (red and green symbols) in which the previously measured values of $k_{1}$ at high temperatures [10] have been added (blue symbols). Table 3 displays the specific reaction conditions for reaction vessels "a" and "c" with additional details given in Table A1 (Appendix). Figure 3 presents an Arrhenius plot of $k_{1}$ obtained in previous [10] and present work together with the available literature values of Seetula et al. [11] and Hartley and Benson [53]. It is obvious that the data represented by the blue squares do not follow a simple straight line, and the extended temperature range of the Knudsen flow reactor 
Table 2: Rate parameters ${ }^{\mathrm{a}}$ obtained in reactors "a" and "c", wall-catalyzed loss $k_{w}$, ratio $k_{w} / k_{e}$.

\begin{tabular}{|c|c|c|c|c|c|c|c|}
\hline \multirow[t]{2}{*}{ Reaction } & \multirow{2}{*}{$\begin{array}{r}A \\
\left(\mathrm{~cm}^{3} \text { molecule }^{-1} \mathrm{~s}^{-1}\right)\end{array}$} & \multirow{2}{*}{$\begin{array}{r}E_{\mathrm{a}} \\
(\mathrm{kJ} / \mathrm{mol})\end{array}$} & \multicolumn{3}{|c|}{$k_{w}\left(\mathrm{~s}^{-1}\right)$} & \multirow[b]{2}{*}{$213 \mathrm{~K}$} & \multirow{2}{*}{$\begin{array}{r}k_{w} / k_{e} \\
\min -\max \end{array}$} \\
\hline & & & $293 \mathrm{~K}$ & $273 \mathrm{~K}$ & $243 \mathrm{~K}$ & & \\
\hline \multicolumn{8}{|c|}{$\mathrm{C}_{2} \mathrm{H}_{5}^{\cdot}+\mathrm{HI} \rightarrow \mathrm{C}_{2} \mathrm{H}_{6}+\mathrm{I}^{\bullet}$} \\
\hline Reactor a & $3.33 \times 10^{-12}$ & 3.78 & 0.53 & 0.57 & 0.64 & 0.74 & $0.16-0.61$ \\
\hline Reactor c & $3.42 \times 10^{-12}$ & 4.26 & & & & & \\
\hline
\end{tabular}

${ }^{a}$ Corresponding ethyl free radical wall-loss reaction constants $k_{\mathrm{w}}$ for $T \geq 293 \mathrm{~K}$ may be found in [10].

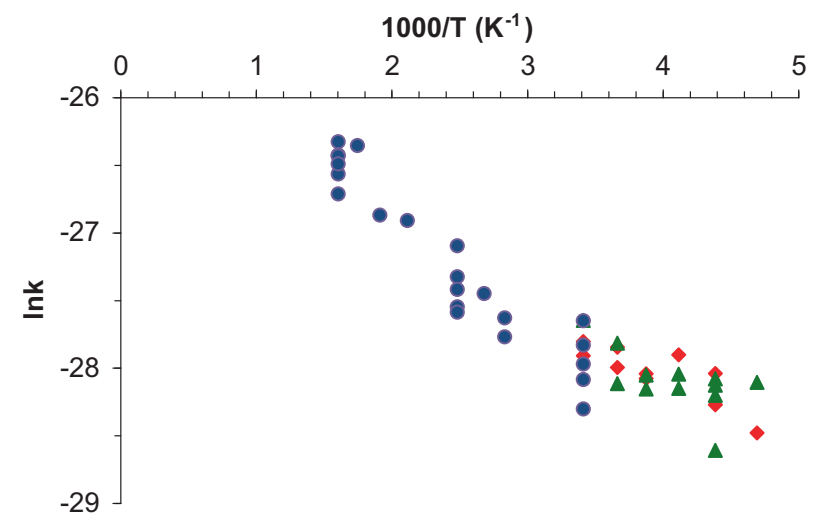

Figure 2: Arrhenius plots for $\mathrm{C}_{2} \mathrm{H}_{5}^{\cdot}+\mathrm{HI} \rightarrow \mathrm{C}_{2} \mathrm{H}_{6}+\mathrm{I}^{*}$ with $k_{w}$ correction. $\bullet$ High temperature results previously published ([10]), present low temperature results obtained in reactor "c", $\Delta$ present low temperature results obtained in reactor "a".

data necessitates the introduction of an additional parameter in order to suitably describe the temperature dependence of $k_{1}$. This point is emphasized in Figure 4 which displays a straight Arrhenius line in comparison with a three-parameter fit of the temperature dependence of the consolidated data for $k_{1}$ obtained using a Knudsen flow reactor in previous [10] and present work. The simple twoparameter and three parameter fits are given in Equations (10) and (11), respectively:

$$
\begin{gathered}
k_{1}=(6.77 \pm 0.79) 10^{-12} \exp (-(4939 \pm 289) / R T) \\
R=8.314 \mathrm{~J} \mathrm{~mol}^{-1} \mathrm{~K}^{-1} \\
k_{1}=(1.89 \pm 1.19) 10^{-13}(T / 298)^{2.92 \pm 0.51} \exp ((3570 \pm 1500) / R T) \\
R=8.314 \mathrm{~J} \mathrm{~mol}^{-1} \mathrm{~K}^{-1}
\end{gathered}
$$

In view of the sizable temperature range 213 to $623 \mathrm{~K}$, it is unsurprising that equation (11) is a better representation of the temperature dependence of $k_{1}$ compared to Equation (10) as displayed in Figure 4. In any case, the present low-temperature data for $k_{1}$ obtained in a Knudsen flow reactor seem to confirm the low rate con- 
Table 3: Summary table of reaction conditions for titration of ethyl by HI (see Appendix Table S1 for complete information). The rate constant $k_{1}$ includes correction for $k_{w}$ (Table 2).

\begin{tabular}{|c|c|c|c|c|c|c|}
\hline $\begin{array}{l}T \\
\text { (K) }\end{array}$ & $\begin{array}{r}\text { Inlet flow } \\
\text { of } \mathrm{C}_{2} \mathrm{H}_{5}^{\circ} \\
\left(\text { molec s }^{-1}\right)\end{array}$ & $\begin{array}{r}{\left[\mathrm{C}_{2} \mathrm{H}_{5}\right]_{0}} \\
\left(\mathrm{molec} \mathrm{cm}^{-3}\right)\end{array}$ & $\begin{array}{r}\text { [total }]_{0} \\
\left(\text { molec cm }^{-3}\right)\end{array}$ & $\begin{array}{r}{[\mathrm{HI}]_{\max }} \\
\left(\operatorname{molec} \mathrm{cm}^{-3}\right)\end{array}$ & $\begin{array}{r}k_{1} \\
\left(\mathrm{~cm}^{3} \mathrm{~s}^{-1} \mathrm{molec}^{-1}\right)\end{array}$ & $\begin{array}{r}\text { Error } \\
(\%)\end{array}$ \\
\hline
\end{tabular}

\begin{tabular}{|c|c|c|c|c|c|c|}
\hline \multicolumn{7}{|c|}{ Knudsen Flow Reactor a $\left(V=213 \mathrm{ml}\right.$, exit aperture $\left.=3.5 \mathrm{~mm}, k_{\mathrm{esc}}\left(\mathrm{s}^{-1}\right)=1.034 \times(T / M)^{1 / 2}\right)$} \\
\hline 213 & $4.59 \times 10^{13}$ & $7.68 \times 10^{10}$ & $2.49 \times 10^{12}$ & $3.15 \times 10^{13}$ & $6.23 \times 10^{-13}$ & 18 \\
\hline 228 & $4.97 \times 10^{13}$ & $8.04 \times 10^{10}$ & $2.39 \times 10^{12}$ & $1.25 \times 10^{13}$ & $6.09 \times 10^{-13}$ & 46 \\
\hline 228 & $4.48 \times 10^{13}$ & $7.25 \times 10^{10}$ & $1.97 \times 10^{12}$ & $1.62 \times 10^{13}$ & $6.38 \times 10^{-13}$ & 64 \\
\hline 228 & $4.30 \times 10^{13}$ & $6.96 \times 10^{10}$ & $2.07 \times 10^{12}$ & $7.92 \times 10^{12}$ & $3.77 \times 10^{-13}$ & 61 \\
\hline 228 & $5.40 \times 10^{13}$ & $8.74 \times 10^{10}$ & $2.41 \times 10^{12}$ & $2.13 \times 10^{13}$ & $5.65 \times 10^{-13}$ & 35 \\
\hline 243 & $2.07 \times 10^{13}$ & $3.24 \times 10^{10}$ & $1.35 \times 10^{12}$ & $1.30 \times 10^{13}$ & $6.61 \times 10^{-13}$ & 51 \\
\hline 243 & $3.49 \times 10^{13}$ & $5.47 \times 10^{10}$ & $1.80 \times 10^{12}$ & $1.27 \times 10^{13}$ & $5.95 \times 10^{-13}$ & 76 \\
\hline 258 & $2.55 \times 10^{13}$ & $3.88 \times 10^{10}$ & $1.35 \times 10^{12}$ & $1.65 \times 10^{13}$ & $6.56 \times 10^{-13}$ & 83 \\
\hline 258 & $2.70 \times 10^{13}$ & $4.10 \times 10^{10}$ & $1.27 \times 10^{12}$ & $1.04 \times 10^{13}$ & $5.93 \times 10^{-13}$ & 119 \\
\hline 273 & $6.38 \times 10^{13}$ & $9.44 \times 10^{10}$ & $1.89 \times 10^{12}$ & $1.98 \times 10^{13}$ & $8.32 \times 10^{-13}$ & 59 \\
\hline 273 & $3.32 \times 10^{13}$ & $4.92 \times 10^{10}$ & $1.35 \times 10^{12}$ & $2.80 \times 10^{13}$ & $6.17 \times 10^{-13}$ & 55 \\
\hline 293 & $3.52 \times 10^{13}$ & $5.03 \times 10^{10}$ & $1.36 \times 10^{12}$ & $1.98 \times 10^{13}$ & $9.85 \times 10^{-13}$ & 29 \\
\hline
\end{tabular}

Knudsen Flow Reactor c $\left(V=272.6 \mathrm{ml}\right.$, exit aperture $\left.=2.0 \mathrm{~mm}, k_{\mathrm{esc}}\left(\mathrm{s}^{-1}\right)=0.441 \times(T / M)^{1 / 2}\right)$

\begin{tabular}{lllllll}
213 & $3.18 \times 10^{13}$ & $9.75 \times 10^{10}$ & $3.58 \times 10^{12}$ & $2.59 \times 10^{13}$ & $4.28 \times 10^{-13}$ & 80 \\
228 & $4.36 \times 10^{13}$ & $1.29 \times 10^{11}$ & $4.12 \times 10^{12}$ & $2.96 \times 10^{13}$ & $6.64 \times 10^{-13}$ & 68 \\
228 & $5.23 \times 10^{13}$ & $1.55 \times 10^{11}$ & $4.44 \times 10^{12}$ & $2.91 \times 10^{13}$ & $5.27 \times 10^{-13}$ & 32 \\
243 & $2.72 \times 10^{13}$ & $7.83 \times 10^{10}$ & $3.40 \times 10^{12}$ & $2.03 \times 10^{13}$ & $7.62 \times 10^{-13}$ & 56 \\
258 & $4.29 \times 10^{13}$ & $1.20 \times 10^{11}$ & $3.04 \times 10^{12}$ & $3.05 \times 10^{13}$ & $6.63 \times 10^{-13}$ & 45 \\
258 & $3.03 \times 10^{13}$ & $8.46 \times 10^{10}$ & $2.59 \times 10^{12}$ & $2.80 \times 10^{13}$ & $6.40 \times 10^{-13}$ & 91 \\
273 & $4.33 \times 10^{13}$ & $1.17 \times 10^{11}$ & $3.29 \times 10^{12}$ & $3.11 \times 10^{13}$ & $6.94 \times 10^{-13}$ & 23 \\
273 & $2.92 \times 10^{13}$ & $7.90 \times 10^{10}$ & $2.48 \times 10^{12}$ & $2.10 \times 10^{13}$ & $8.07 \times 10^{-13}$ & 34 \\
293 & $4.72 \times 10^{13}$ & $1.23 \times 10^{11}$ & $2.98 \times 10^{12}$ & $2.03 \times 10^{13}$ & $7.57 \times 10^{-13}$ & 52 \\
293 & $4.09 \times 10^{13}$ & $1.07 \times 10^{11}$ & $2.79 \times 10^{12}$ & $2.46 \times 10^{13}$ & $8.41 \times 10^{-13}$ & 66 \\
\hline
\end{tabular}

stant associated to a small positive activation energy in contrast to data obtained in laminar flow tubes using pulsed photolysis from a suitable precursor ([11] and Figure 4). Of note is the negative temperature dependence of the exponential term in the three parameter fit that may not be confused with an Arrhenius activation energy. Apparently the increase in the rate constant with temperature is "distributed" between the $(T / 298)^{\mathrm{n}}$ and the terminal exponential term. 


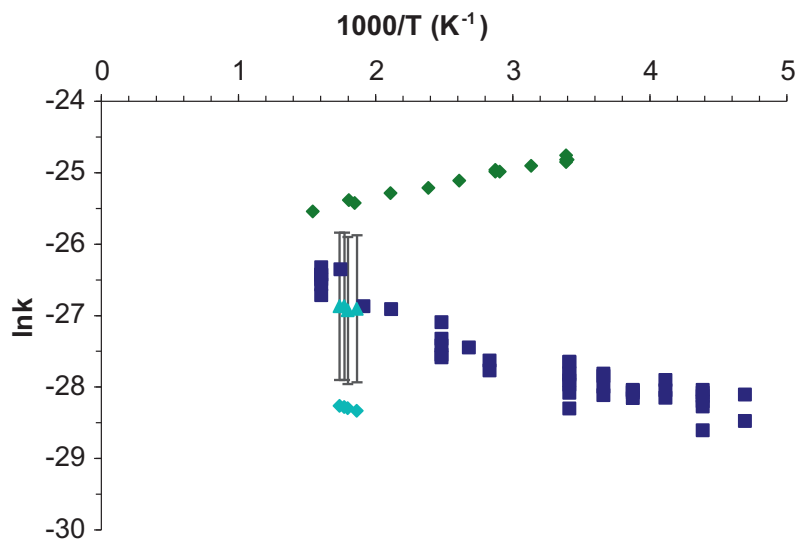

Figure 3: Comparison of Arrhenius plots of present data with previously published $k$ $\left(\mathrm{C}_{2} \mathrm{H}_{5}^{-}+\mathrm{HI} \rightarrow \mathrm{C}_{2} \mathrm{H}_{6}+\mathrm{I}^{\circ}\right)$ under all investigated conditions; present work, $\diamond$ Seetula et al. [11], - Hartley and Benson [53], $\Delta$ Hartley and Benson recalculated based on work published in $[65,66]$. Uncertainties reflect the disagreement between the studies of Hunter and Kristiansson [65] and Hayes and Strong [66].

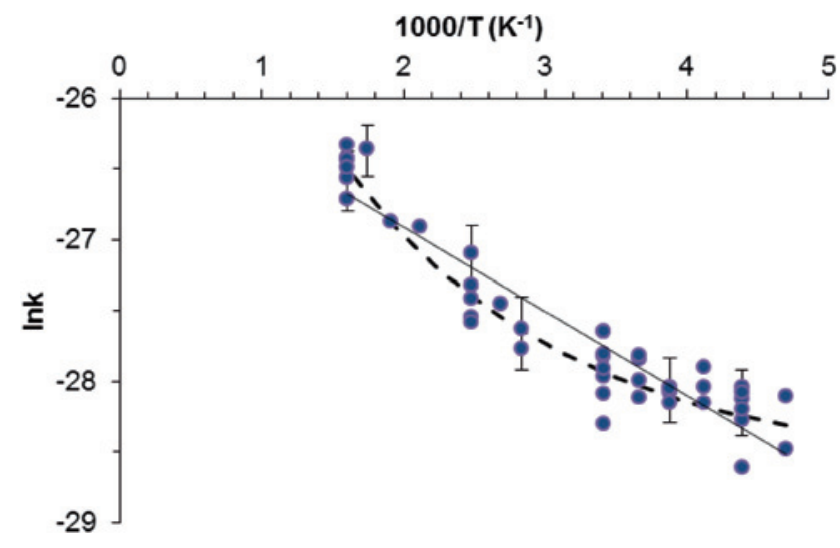

Figure 4: Comparison between linear fit (Arrhenius) and non-linear three parameter fit to combined data across the full temperature range 213-623 K: Arrhenius (full) line: $\left(k_{1}=(6.77 \pm 0.79) 10^{-12} \exp ((-4940 \pm 289) / R T)\right.$, three-parameter (non-linear) fit (broken line): $\left(k_{1}=(1.89 \pm 1.19) 10^{-13}(T / 298)^{2.92 \pm 0.51} \exp ((3570 \pm 1500) / R T)\right.$ with $R=8.314 \mathrm{~J} \mathrm{~K}^{-1} \mathrm{~mol}^{-1}$. The experimental uncertainty corresponds to the $2 \sigma$ level whose numerical values are displayed in Table 3 and in reference [10] (Table 6). 
Table 4: Essential structural parameters and imaginary vibrational frequencies for the transition state and molecular complexes calculated at the CCSD/cc-pVDZ level of theory and CASPT2/RASSI/ANO-RCC spin-orbit corrections.

\begin{tabular}{|c|c|c|c|}
\hline parameter & MCR & TS & MCP \\
\hline$r(\mathrm{C}-\mathrm{H}), \AA$ & 2.403 & 1.872 & 1.093 \\
\hline$r(\mathrm{I}-\mathrm{H}), \AA$ & 1.621 & 1.661 & 3.909 \\
\hline$\theta(\mathrm{OHC}), \stackrel{\circ}{ }$ & 170.4 & 175.7 & 127.4 \\
\hline$L^{\mathrm{a}}$ & & 0.061 & \\
\hline$v^{\#}, \mathrm{~cm}^{-1}$ & & $165 \mathrm{i}$ & \\
\hline $\mathrm{SO}, \mathrm{kJ} \mathrm{mol}^{-1}$ & -1.69 & -2.06 & -27.02 \\
\hline
\end{tabular}

a The $L$ parameter is defined as the ratio of the increase in the length of the bond being broken and the elongation of the bond being formed, each with respect to its equilibrium value in the reactant and the product. SO is the spin-orbit contribution of the iodine atom in different stages of the reaction.

\section{Wall reactions}

In addition, it is worthwhile to take a closer look at the "other" rate-constant falling out of the evaluation of the raw data $k_{1}^{a}$ and $k_{1}^{c}$, namely $k_{w}^{\mathrm{C}_{2} \mathrm{H}_{5}}$. The discussion of this point is rarely undertaken in the literature for reasons unknown because formal algebra leads to an equal weight of both resulting rate constants and therefore $k_{1}$ does not carry more weight than $k_{w}^{\mathrm{C}_{2} \mathrm{H}_{5}}$. Table 2 together with corresponding data from [10] (Table 4) reveals that $k_{w}^{\mathrm{C}_{2} \mathrm{H}_{5}}$ increases with decreasing temperature in a systematic way, in seeming contrast to the case of t$\mathrm{C}_{4} \mathrm{H}_{9}^{\circ}$ free radical (see Table 3 in ref. [12]). After scaling (down) the high temperature data (298 to $623 \mathrm{~K}$ ) [10], one observes an increase of $k_{w}^{\mathrm{C}_{2} \mathrm{H}_{5}}$ (from 0.37 to $0.74 \mathrm{~s}^{-1}$ ) when going from 623 to $213 \mathrm{~K}$. The scaling down of the previous high-temperature values of $k_{w}^{\mathrm{C}_{2} \mathrm{H}_{5}}$ [10] by a factor of 1.52 was necessary because the present low-temperature and previous high-temperature measurements were temporally spaced apart by several months during which the state of the surface coating of the reaction vessels may have changed considerably. Frequent use of the reaction vessel usually leads to a decrease in $k_{w}^{\mathrm{C}_{2} \mathrm{H}_{5}}$ owing to passivation of the walls. Conversely, a scaling up of the present low-temperature values might have been undertaken with equal justification. In terms of a qualitative interpretation one may state that the observed increase of wall-loss of ethyl free radical with decreasing temperature by a factor of two probably has to do with increasing 
physi-sorption of ethyl on the cold FEP-coated internal vessel walls at low temperature. This behavior is analogous to benzyl $\left(\mathrm{C}_{7} \mathrm{H}_{7}^{*}\right)$ free radical inside a Knudsen flow reactor that physi-sorbs onto the ambient temperature vessel walls from which it may be desorbed back into the gas phase by heating the walls of the reaction vessel [54]. It may, however, be difficult to compare the absolute values of $k_{w}^{\mathrm{C}_{2} \mathrm{H}_{5}}$ resulting from this work with corresponding values originating from laminar flow tube work. Taking the work of Seetula et al. as an example for ethyl free radical [11], one is led to the following conclusions: the absolute value of $k_{w}^{\mathrm{C}_{2} \mathrm{H}_{5}}$ is roughly a factor of 15 to 20 larger than the present value at $293 \mathrm{~K}$, similar to the increase in $k_{1}$. In addition, there does not seem to be a systematic variation with temperature nor a dependence of $k_{w}^{\mathrm{C}_{2} \mathrm{H}_{5}}$ on the type of surface coating. This raises the question as to the nature of $k_{w}^{\mathrm{C}_{2} \mathrm{H}_{5}}$ obtained in the laminar flow tube experimental series of measurements and whether $k_{w}^{\mathrm{C}_{2} \mathrm{H}_{5}}$ may be compared to the present measurements. Second-order wall reactions between adsorbed reactants are often invoked in cases where at least one of the reactants are "sticky" which means that its adsorption lifetime or surface residence time on the vessel wall is of the same order of magnitude or larger than the gas residence time. However, we have not observed any kinetics that would suggest such second-order wall reactions for the reaction of interest throughout the used temperature range.

A look into typical literature values for wall-loss rate constants of free radicals may be helpful in this regard when dealing with similar free radicals studied by applying either discharge-flow techniques such as laminar flow tube or Knudsen flow reactors. All reaction vessels had some sort of coating to minimize free radical wall losses. Starting from low to high absolute values of the wall-loss rate constants we have $k_{w}^{\mathrm{O}}=0 \mathrm{~s}^{-1}$ for the reaction $\mathrm{O}\left({ }^{3} \mathrm{P}\right)+\mathrm{NO}_{2} \rightarrow \mathrm{NO}+\mathrm{O}_{2}$ performed in a typical discharge flow-resonance fluorescence apparatus [55]. This is not too surprising because ground state oxygen atoms at low- to ambient temperatures are thermally nonreactive. Mellouki et al. have measured $k_{w}^{\mathrm{HO}_{2}}=2 \mathrm{~s}^{-1}$ with an upper limit of $4 \mathrm{~s}^{-1}$ in the range 300 to $441 \mathrm{~K}$ [56] in the reaction $\mathrm{HO}_{2}^{\circ}+\mathrm{BrO}^{\circ}$ using a discharge flow reactor equipped with Laser Magnetic Resonance (LMR) detection. Bedjanian et al. have measured $k_{w}^{\mathrm{OH}}=3-10$ and $k_{w}^{\mathrm{HO}_{2}}=4-10 \mathrm{~s}^{-1}$ in the range $230-320 \mathrm{~K}$ using a discharge-flow experiment equipped with modulated molecular beam mass spectrometric detection in their study of the $\mathrm{OH}^{\circ}+\mathrm{ClO}^{\circ}$ reaction [57]. It is not clear from the report whether or not the $k_{w}$ values follow some sort of temperature dependence or whether the given limits are associated with a high or low temperature. A discharge-flow study of the selfreaction of $\mathrm{IO}^{\circ}$ at $300 \mathrm{~K}$ by Vipond et al. [58] led to $k_{w}^{\mathrm{IO}}=6-8 \mathrm{~s}^{-1}$ whereas a study of ${ }^{\circ} \mathrm{CH}_{2} \mathrm{OH}$ free radical reactivity with $\mathrm{O}_{2}$ performed by Dobé et al. [59] resulted in $k_{w}^{\mathrm{CH}_{2} \mathrm{OH}}=$ $29 \pm 5 \mathrm{~s}^{-1}$. In this latter study the pseudo first-order rate as a function of the oxygen concentration linearly went through the origin despite the propensity of ${ }^{\circ} \mathrm{CH}_{2} \mathrm{OH}$ 
free radical to lose atomic $\mathrm{H}$ to convert into $\mathrm{CH}_{2} \mathrm{O}$. Based on the straight first-order line one may have concluded that fast wall-catalyzed reactions of ${ }^{\circ} \mathrm{CH}_{2} \mathrm{OH}$ were absent. However, the published value given above resulted from computer simulations that "needed" a significant wall-loss for ${ }^{\circ} \mathrm{CH}_{2} \mathrm{OH}$ (hydroxymethyl free radical). At the limiting upper end of wall-catalyzed loss reaction rate constants for ethyl radical we may cite a study by Golden et al. that dealt with the recombination of ethyl free radical at higher temperature in a gold-coated Knudsen flow reactor with $k_{w}^{\mathrm{C}_{2} \mathrm{H}_{5}}=11$ and $17 \mathrm{~s}^{-1}$ at 843 and $878 \mathrm{~K}$, respectively [60].

Finally, Dobis and Benson generated ethyl free radical through $\mathrm{H}$ abstraction by atomic $\mathrm{Cl}^{\circ}$ in a Knudsen flow reactor [61] in the range 203 to $343 \mathrm{~K}$. In agreement with our present results they did not report a value for $k_{w}^{\mathrm{C}_{2} \mathrm{H}_{5}}$, simply because it is too small a value to be measured in the complex $\mathrm{C}_{2} \mathrm{H}_{6} / \mathrm{Cl}^{\circ}$ chemical system. However, they did not observe the ethyl recombination product $n-\mathrm{C}_{4} \mathrm{H}_{10}$ whereas the disproportionation products $\mathrm{C}_{2} \mathrm{H}_{6}$ and $\mathrm{C}_{2} \mathrm{H}_{4}$ were easily observed. The reason for the opposite temperature dependence of $k_{w}$ for ethyl obtained in the present and previous [10] study and t-butyl free radical [12], namely decreasing and increasing with temperature, respectively, is by no means clear but may have to do with fast secondary reactions of atomic chlorine with n-butane, the recombination product. Of note is the identical $\mathrm{C}-\mathrm{H}$ bond strength for both free radicals leading to the corresponding olefin, which therefore cannot be used as a guide for the differing temperature trend of radical stability. In conclusion, the large value of $k_{w}^{\mathrm{C}_{2} \mathrm{H}_{5}}$ obtained in the laminar flow tube work of Seetula et al. [11] is not unusual in comparison to similar investigations of other free radicals, although it is rather large at the high-end of the range and does not have a definite temperature trend as $k_{w}^{\mathrm{C}_{2} \mathrm{H}_{5}}$ resulting from the present study. This raises the question whether or not the mechanism is identical to the one observed in Knudsen flow reactors. Of note is further the low absolute value of $k_{w}^{\mathrm{C}_{2} \mathrm{H}_{5}}$ throughout the studied temperature range investigated in this and the previous work on Reaction (R1) [10]. Both $k_{1}$ and $k_{w}^{\mathrm{C}_{2} \mathrm{H}_{5}}$ seem to be a factor of approximately 20 larger in the work of Seetula et al. [11] compared to the results of the present combined with the previous study [10] (Table 2).

\section{Theoretical calculations}

All molecular data relevant to ab initio calculations are summarized in Tables 4 and 5 and also in Supplementary Information, Tables S2 to S8 and Figure S1.

The energy profile for Reaction (R1) is displayed in Figure 5 and is based on data presented in Table 5. Similar to the bromine analog of Reaction (R1), namely $\mathrm{C}_{2} \mathrm{H}_{5}^{*}+\mathrm{HBr}$, presented by Golden et al. [8], the present electronic structure cal- 


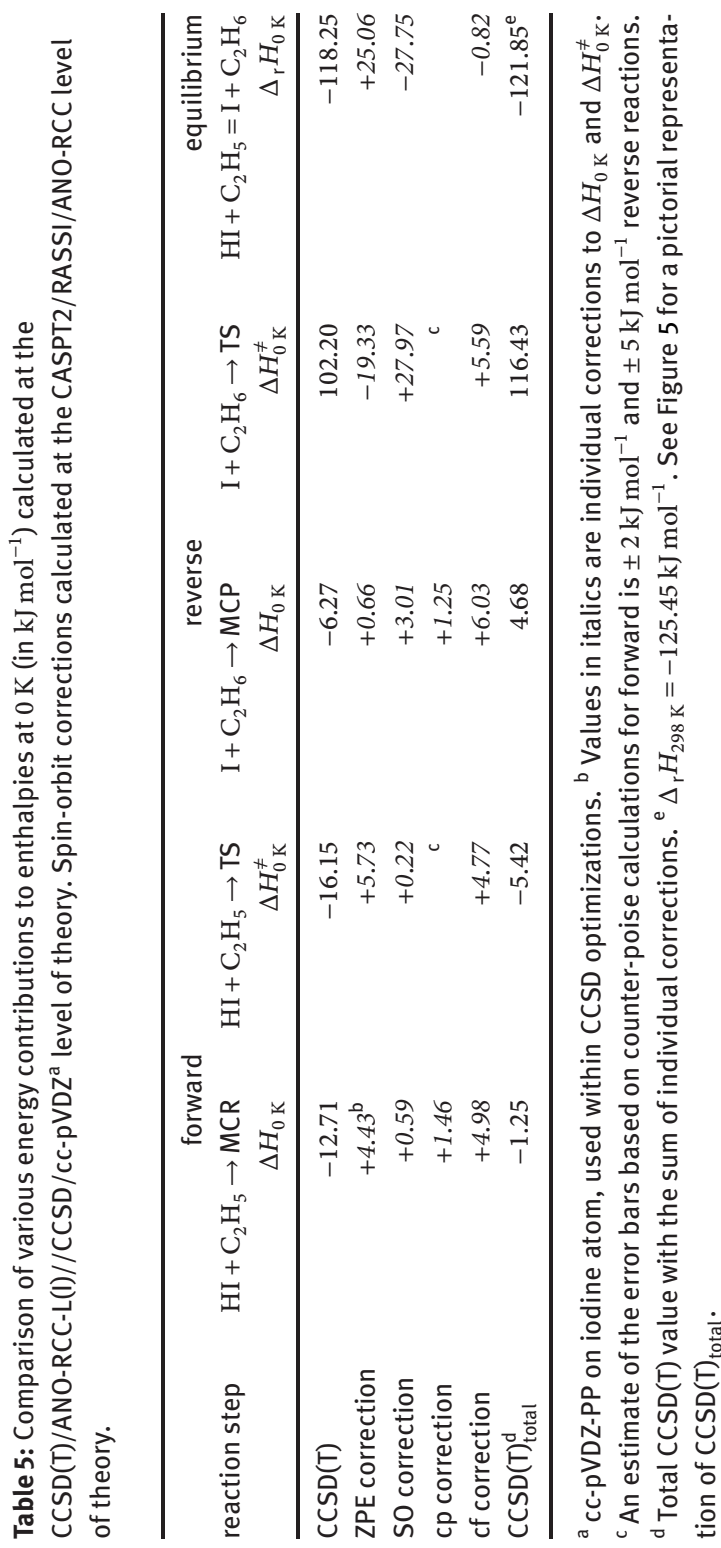

culation leads to two molecular adducts MCR and MCP separated by a transition state whose potential energy is lower by $4.17 \mathrm{~kJ} \mathrm{~mol}^{-1}$ relative to MCR, itself more stable than the reactants by only $1.25 \mathrm{~kJ} \mathrm{~mol}^{-1}$ (Figure 5). In contrast, for the bromine analog of Reaction (R1) the molecular adduct MCR is stabilized by $9.70 \mathrm{~kJ} \mathrm{~mol}^{-1}$ relative to the reactants, with MCR itself more stable than TS by 
ENERGY DIAGRAM $\left(\Delta \mathrm{H}_{\mathrm{r}}^{0}\right.$ at $\left.0 \mathrm{~K} / \mathrm{kJ} \mathrm{mol}^{-1}\right)$ for Reaction $\mathrm{C}_{2} \mathrm{H}_{5}{ }^{*}+\mathrm{HI}^{\leftrightarrows} \mathrm{C}_{2} \mathrm{H}_{6}+\mathrm{l}^{*}$

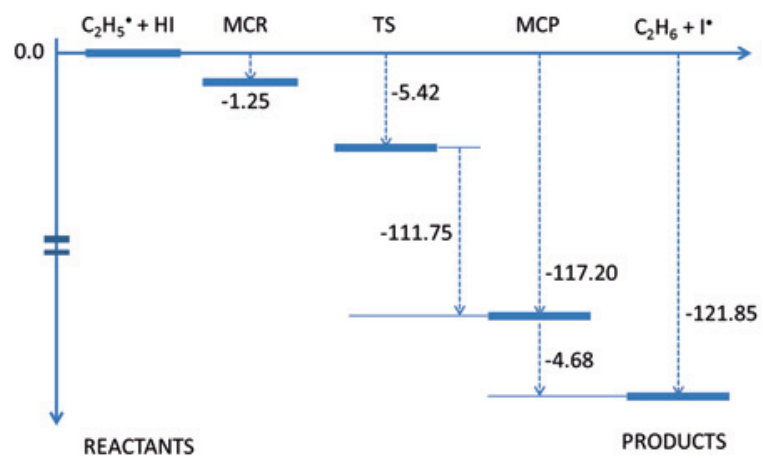

Figure 5: Energy Diagram at $T=0 \mathrm{~K}$ for the complex mechanism of Reaction (R1) using the results displayed in Table 5 (reaction enthalpy $\Delta H_{\mathrm{r}}^{0}$ at $0 \mathrm{~K}$ equals free energy change at $0 \mathrm{~K}$ on ordinate. Of note is the fact that the ordinate is "broken", that is discontinuous between "TS" and "MCP"). MCR, TS and MCP correspond to Molecular Complex in the entrance channel, Transition State and Molecular Complex in the exit channel when following the reaction from reactants $\left(\mathrm{C}_{2} \mathrm{H}_{5}^{\circ}+\mathrm{HI}\right)$ to products $\left(\mathrm{C}_{2} \mathrm{H}_{6}+\mathrm{I}^{\circ}\right)$.

a mere $0.58 \mathrm{~kJ} \mathrm{~mol}^{-1}$. This represents a significant difference to the present treatment of Reaction (R1) and needs to be critically evaluated in light of possible differences in computational protocols between Golden et al. and the present theoretical method. The reaction enthalpy $\Delta_{r} H_{298 \mathrm{~K}}^{0}$ has also been calculated using the literature standard heats of formation $\Delta_{\mathrm{f}} H_{0 \mathrm{~K}}^{0}$ of the species of interest (see Appendix Table $\mathrm{S} 5$ for data and relevant references). The calculated reaction enthalpy at the CCSD(T)/ANO-RCC-L(I)//CCSD/cc-pVDZ level of theory including all possible corrections $\left(-125.45 \mathrm{~kJ} \mathrm{~mol}^{-1}\right.$, Table 5 , footnote e) is in excellent agreement with its experimental counterpart $\left(-124.49 \mathrm{~kJ} \mathrm{~mol}^{-1}\right.$, Table S5).

Figure 6 presents the computed $k_{1}$ values as a function of temperature for different levels of theory, both for the direct and complex mechanisms. We also tested the influence of the kinetic theory using variational transition state theory using the direct mechanism and the rigid rotor harmonic oscillator (RRHO) approximation [62] as implemented in the GPOP software [51]. 50 points on the Minimum Energy Path (MPE) were used (25 and 25 in the forward and reverse directions, respectively). For all these points, $\mathrm{SO}$ effects are close to that of the TS structure, the difference between the edge points in MPE does not exceed $0.6 \mathrm{~kJ} \mathrm{~mol}^{-1}$. As may be seen in Figure 6, the use of either TST or VTST model leads to calculated rate constants very close to each other. The largest differences $(<30 \%)$ may be noted at high temperatures. The corresponding numerical values are displayed 


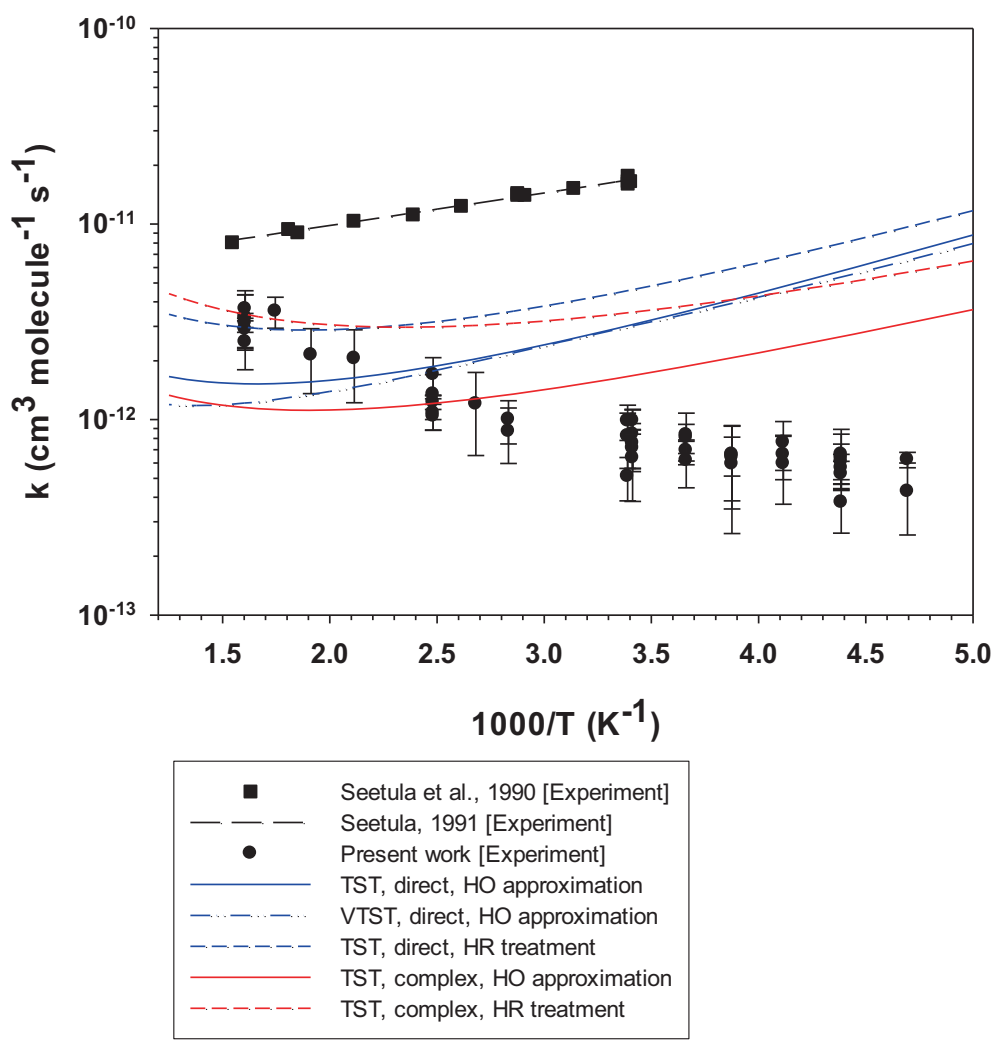

Figure 6: Temperature dependence of the rate constant of the forward reaction $\mathrm{HI}+{ }^{\circ} \mathrm{C}_{2} \mathrm{H}_{5} \rightarrow \mathrm{I}^{\bullet}+\mathrm{C}_{2} \mathrm{H}_{6}$ calculated at the CCSD(T)/ANO-RCC-L(I)//CCSD/cc-pVDZ level of theory with different kinetic models. Comparison with present experimental data together with available literature data.

in the Appendix, Tables S6 and S7. The best agreement is achieved for the complex pathway and the hindered rotor treatment of the internal rotations, both in the transition state TS and the MCR adduct. The corresponding broken red line in Figure 6 comes closest to the average of the high temperature experimental data for $k_{1}$ and is approximately larger than the average taken at $300 \mathrm{~K}$ by a factor of five. The corresponding harmonic oscillator model as well as the direct reaction pathway results liee significantly below the calculated values of $k_{1}$ and rejoin the experimental data in the neighborhood of $400 \mathrm{~K}$. However, the temperature trend of $k_{1}$ is not captured correctly in this low temperature range although every theoretical treatment of varying complexity dealing with this kind of chemical activation mechanism shows this negative temperature dependence at variance with the experimental result in contrast to the situation for $\mathrm{CH}_{3}^{*}+\mathrm{HI}[9]$. 


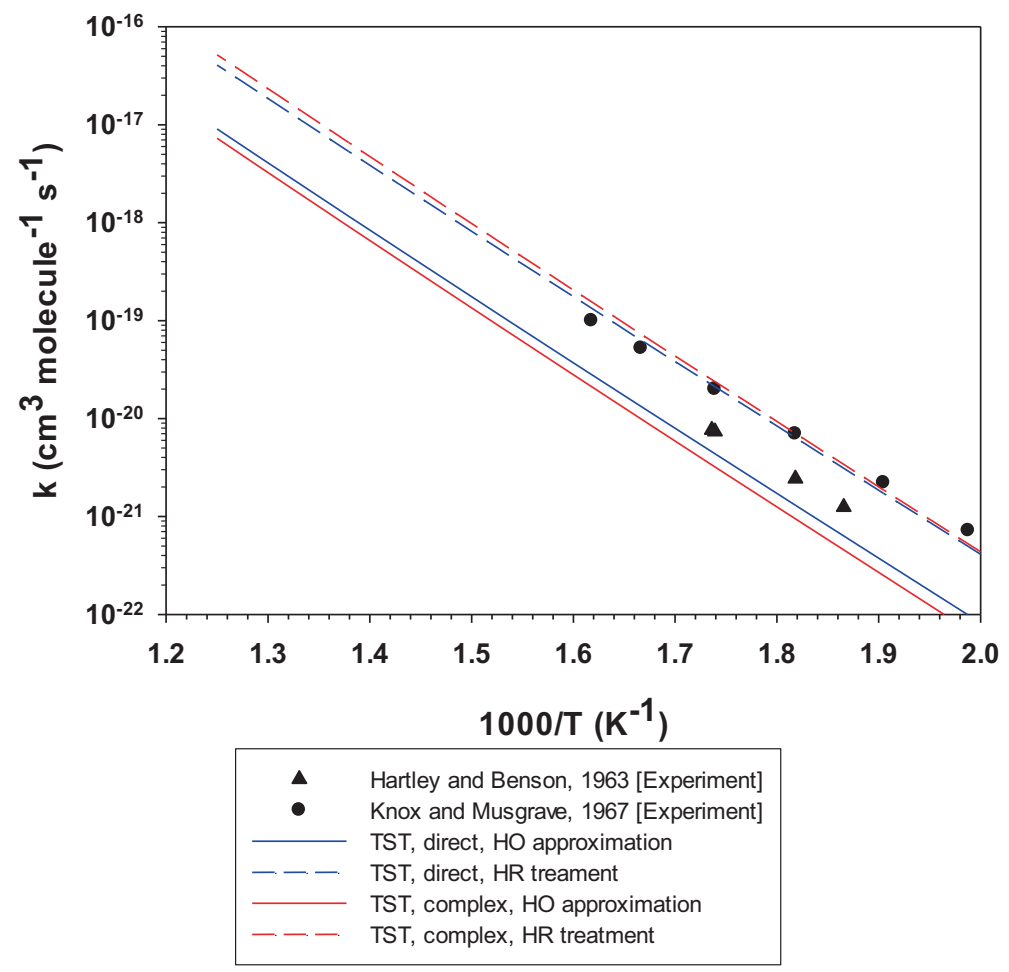

Figure 7: Temperature dependence of the rate constant of the reverse reaction $\mathrm{I}^{\bullet}+\mathrm{C}_{2} \mathrm{H}_{6} \rightarrow \mathrm{HI}+{ }^{\circ} \mathrm{C}_{2} \mathrm{H}_{5}$ calculated at the CCSD(T)/ANO-RCC-L(I)//CCSD/cc-pVDZ level of theory. Comparison with the available two sets of literature data that do not provide the associated uncertainty limits of the experimental data.

However, all calculations switch to a positive temperature dependence of $k_{1}$ at some higher temperature, the turnover temperature being a function of the type of calculation. However, Figure 6 also shows that the present four different theoretical calculations of $k_{1}$ are significantly below the experimental data of Seetula et al. [11] even though theory captures well the general negative temperature dependence from the lowest temperature to 550 and $625 \mathrm{~K}$, depending on any of the four methods (see numerical values in Appendix Table S6). Unlike the situation with $\mathrm{CH}_{3}^{\cdot}+\mathrm{HI}[9]$, sophisticated theory is unable to clearly decide which experimental data of Reaction (R1) are accurate. The methyl + HI work just mentioned clearly seems to agree with the recommended rate constants whose values at ambient temperature are lower by a factor of six compared to laminar flow work by Seetula et al. [11] whereas in the present case the situation is not as clear cut as in the methyl radical case. Nevertheless, it seems that the absolute value of $k_{1}$ is 
more in agreement with the present data set whereas the temperature dependence seems to speak for the accuracy of the data of Seetula et al. [11]. In short, theory and experiments are at odds with each other.

Figure 7 finally shows the results for the inverse of Reaction (R1), namely $k_{-1}$ as a function of temperature calculated by the four variants listed above, namely direct and complex pathways, both using harmonic oscillators and hindered rotors. The corresponding numerical values may be found in Appendix Table S7. The inverse rate constant $k_{-1}$ has been found by dividing $k_{1}$ by the overall equilibrium constant $K_{e q}=k_{1} / k_{-1}$ for the equilibrium $\mathrm{C}_{2} \mathrm{H}_{5}^{\bullet}+\mathrm{HI} \rightleftarrows \mathrm{C}_{2} \mathrm{H}_{6}+\mathrm{I}^{\bullet}$. Figure 7 shows the excellent agreement of the theoretical results pertaining to both the complex and direct mechanisms coupled to the hindered rotor treatment (broken red and blue lines in Figure 7) with the measurements of Knox and Musgrave of $k_{-1}$ [63] whereas the agreement is less good for the calculations using the harmonic oscillator approximation. The agreement with the data of Hartley and Benson is poor as all calculated $k_{-1}$ values using the hindered rotor model lie significantly above the experimental results [53]. A reaction dynamics or collisional model approach for the reaction $\mathrm{CH}_{3}^{*}+\mathrm{HBr} \rightarrow \mathrm{CH}_{4}+\mathrm{Br}^{\bullet}$ avoids transition state theory altogether and achieves excellent agreement with experimental kinetic results over the temperature range 150 to $1000 \mathrm{~K}$ although a switch between the two collisional models has to be operated "by hand" at $400 \mathrm{~K}$ [64]. The character of the model changes with temperature because for $T<400 \mathrm{~K}$ the reaction mechanism follows a complex-forming pathway whereas at $T>400 \mathrm{~K}$ a direct mechanism leads to a slight positive T-dependence of the rate constant. The minimum energy path of the reaction includes a distinct local minimum in the entrance and exit channels that are significantly larger compared to the present iodine-containing system. The model also explains the vibrational excitation of the product $\mathrm{CH}_{4}$ for the direct high-temperature mechanism in contrast to negligible vibrational excitation for the complex-forming model. The model nicely demonstrates the vastly different lifetimes for the two mechanistic alternatives, that is direct vs. complex that may perhaps be amenable to experimental distinction.

\section{Conclusions}

Thermodynamic and kinetic parameters of the title reaction were studied using a composite approach based on CCSD optimizations and $\operatorname{CCSD}(\mathrm{T})$ single-point energy evaluations with the large ANO-RCC basis set, followed by a number of small energetic corrections. The calculated standard reaction enthalpy at $298 \mathrm{~K}$ $\left(-125.45 \mathrm{~kJ} \mathrm{~mol}^{-1}\right)$ is in excellent agreement with the literature value $(-124.49 \pm$ 
$2.13 \mathrm{~kJ} \mathrm{~mol}^{-1}$ ). Predicted rate constants based on canonical transition state theory including an asymmetric Eckart tunnelling correction are in good agreement with most of the literature data for the forward and reverse reactions. Experimental data of Reaction (R1) taken over a large temperature range seem to agree better with the absolute values of the hindered rotor model for the complex-forming reaction mechanism whereas the associated slightly negative temperature dependence matches the laminar flow tube data of Seetula et al. [11]. Both values of $k_{1}$ and $k_{w}^{\mathrm{C}_{2} \mathrm{H}_{5}}$ at ambient temperature obtained in the present study are smaller by approximately a factor of 20 compared to Seetula et al. [11] albeit without showing a clear temperature dependence of $k_{w}^{\mathrm{C}_{2} \mathrm{H}_{5}}$ in the latter work. Finally, at the present state of progress it is not possible to decide on the basis of a sophisticated quantum chemical model alone which of the two sets of experimental results, namely the work of Seetula et al. [11] or the present, is more accurate despite the rather large difference in $k_{1}$ and $k_{w}^{\mathrm{C}_{2} \mathrm{H}_{5}}$ at ambient temperature.

Acknowledgement: NL and MJR would like to thank the Swiss State Secretariat of Education and Innovation for providing generous funds in the framework of the COST project CM0901 “Cleaner Combustion” through grant SBF No. C11.0052. IČ, KŠ and JF appreciate the support from Slovak Grant Agencies APVV (projects APVV-0059-10 and LPP-0150-09) and VEGA (grant 1/0092/14). MS would like to acknowledge the support from the Ministry of Education, Youth and Sports of the Czech Republic (project No. L01305). Computer time for part of the theoretical calculations was kindly provided by the Centre de Ressources Informatiques de Haute Normandie (CRIHAN) and the Centre de Ressources Informatiques (CRI) of the University of Lille1. FL appreciates the support from the French ANR agency under Contract No. ANR-11-LABX-0005 "Chemical and Physical Properties of the Atmosphere" (CaPPA). MJR would like to acknowledge insightful discussions with John R. Barker (University of Michigan) and David M. Golden (Stanford University) on the relationship between theory and experiment for elementary (or not?) free radical-molecule reactions. We explicitly thank professor John R. Barker for pointing out the possible molecular geometry dependence of the applied SO corrections in the review process. MJR also thanks Dr. Hualin Xiao (PSI) for statistical calculations. 


\section{References}

1. D. M. Golden and S. W. Benson, Chem. Rev. 69 (1969) 125.

2. P. W. Seakins, M. J. Pilling, J. T. Niiranen, D. Gutman, and L. N. Krasnoperov, J. Phys. Chem. 96 (1992) 9847.

3. J. A. Seetula, J. Chem. Soc. Faraday T. 94 (1998) 891.

4. J. M. Nicovich, C. A. Vandijk, K. D. Kreutter, and P. H. Wine, J. Phys. Chem. 95 (1991) 9890.

5. V. M. Ferrell, M.S., M.S. thesis, Georgia Institute of Technology, Atlanta, GA (1998).

6. R. S. Timonen and D. Gutman, J. Phys. Chem. 90 (1986) 2987.

7. R. S. Timonen, J. J. Russell, D. Sarzynski, and D. Gutman, J. Phys. Chem. 91 (1987) 1873.

8. D. M. Golden, J. P. Peng, A. Goumri, J. Yuan, and P. Marshall, J. Phys. Chem. A 116 (2012) 5847.

9. K. Meciarova, M. Sulka, S. Canneaux, F. Louis, and I. Cernusak, Chem. Phys. Lett. 517 (2011) 149.

10. N. Leplat, A. Wokaun, and M. J. Rossi, J. Phys. Chem. A 117 (2013) 11383.

11. J. A. Seetula, J. J. Russell, and D. Gutman, J. Am. Chem. Soc. 112 (1990) 1347.

12. N. Leplat and M. J. Rossi, J. Phys. Chem. A 118 (2014) 5135.

13. N. Leplat and M. J. Rossi, Int. J. Chem. Kinet. 46 (2014) 305.

14. N. Leplat and M. J. Rossi, Rev. Sci. Instrum. 84 (2013) 114104.

15. R. T. Dillon and W. G. Young, J. Am. Chem. Soc. 51 (1929) 2389.

16. J. Čížek, Adv. Chem. Phys. 14 (1969) 35.

17. G. D. Purvis and R. J. Bartlett, J. Chem. Phys. 76 (1982) 1910.

18. G. E. Scuseria, C. L. Janssen, and H. F. Schaefer, J. Chem. Phys. 89 (1988) 7382.

19. G. E. Scuseria and H. F. Schaefer, J. Chem. Phys. 90 (1989) 3700.

20. T. H. Dunning, J. Chem. Phys. 90 (1989) 1007.

21. K. A. Peterson, B. C. Shepler, D. Figgen, and H. Stoll, J. Phys. Chem. A 110 (2006) 13877.

22. Johnson III, R. D. (Ed.), NIST Computational Chemistry Comparison and Benchmark Database, NIST Standard Reference Database Number 101, Release 16a, http://cccbdb. nist.gov/, National Institute of Science and Technology (NIST), Gaithersburg, MD (2013).

23. C. Gonzalez and H. B. Schlegel, J. Chem. Phys. 90 (1989) 2154.

24. C. Gonzalez and H. B. Schlegel, J. Phys. Chem. 94 (1990) 5523.

25. M. J. Frisch, G. W. Trucks, H. B. Schlegel, G. E. Scuseria, M. A. Robb, J. R. Cheeseman, J. A. Montgomery Jr., T. Vreven, K. N. Kudin, J. C. Burant, J. M. Millam, S. S. Iyengar, J. Tomasi, V. Barone, B. Mennucci, M. Cossi, G. Scalmani, N. Rega, G. A. Petersson, H. Nakatsuji, M. Hada, M. Ehara, K. Toyota, R. Fukuda, J. Hasegawa, M. Ishida, T. Nakajima, Y. Honda, O. Kitao, H. Nakai, M. Klene, X. Li, J. E. Knox, H. P. Hratchian, J. B. Cross, V. Bakken, C. Adamo, J. Jaramillo, R. Gomperts, R. E. Stratmann, O. Yazyev, A. J. Austin, R. Cammi, C. Pomelli, J. W. Ochterski, P. Y. Ayala, K. Morokuma, G. A. Voth, P. Salvador, J. J. Dannenberg, V. G. Zakrzewski, S. Dapprich, A. D. Daniels, M. C. Strain, O. Farkas, D. K. Malick, A. D. Rabuck, K. Raghavachari, J. B. Foresman, J. V. Ortiz, Q. Cui, A. G. Baboul, S. Clifford, J. Cioslowski, B. B. Stefanov, G. Liu, A. Liashenko, P. Piskorz, I. Komaromi, R. L. Martin, D. J. Fox, T. Keith, M. A. Al-Laham, C. Y. Peng, A. Nanayakkara, M. Challacombe, P. M. W. Gill, B. Johnson, W. Chen, M. W. Wong, C. Gonzalez, and J. A. Pople, Gaussian 03, Revision D.01, Gaussian Inc., Wallingford, CT (2004).

26. D. A. McQuarrie, Statistical Mechanics, Harper \& Row, New York (1976).

27. J. Pfaendtner, X. Yu, and L. Broadbelt, Theor. Chem. Acc. 118 (2007) 881. 
28. J. Pfaendtner, X. Yu, and L. J. Broadbelt, Calctherm, version 0. 9, Northwestern University, Evanston, IL (2005).

29. K. S. Pitzer, Discuss. Faraday Soc. 10 (1951) 66.

30. F. Aquilante, L. De Vico, H. Ferre, G. Ghigo, P. A. Malmqvist, P. Neogrady, T. Pedersen, M. Pitonak, M. Reiher, B. Roos, L. Serrano-Andrés, M. Urban, V. Veryazov, and R. Lindh, J. Comput. Chem. 31 (2010) 224.

31. B. Roos, R. Lindh, P.-A. Malmqvist, V. Veryazov, and P. O. Widmark, J. Phys. Chem. A 108 (2004) 2851.

32. M. Urban, P. Neogrady, J. Raab, and G. H. F. Diercksen, Collect. Czech. Chem. C. 63 (1998) 1409.

33. M. Medved, M. Urban, V. Kello, and G. H. F. Diercksen, J. Mol. Struct.-Theochem 547 (2001) 219.

34. D. Z. Goodson, J. Chem. Phys. 116 (2002) 6948.

35. K. Meciarova, L. Cantrel, and I. Cernusak, Collect. Czech. Chem. C. 73 (2008) 1340.

36. A. W. Jasper, S. J. Klippenstein, and L. B. Harding, J. Phys. Chem. A 114 (2010) 5759.

37. F. Louis, I. Cernusak, S. Canneaux, and K. Meciarova, Comput. Theor. Chem. 965 (2011) 275.

38. K. Sulkova, M. Sulka, F. Louis, and P. Neogrady, J. Phys. Chem. A 117 (2013) 771.

39. M. Sulka, K. Sulkova, F. Louis, P. Neogrady, and I. Cernusak, Z. Phys. Chem. 227 (2013) 1337.

40. B. Roos and P.-A. Malmqvist, Phys. Chem. Chem. Phys. 6 (2004) 2919.

41. B. O. Roos, K. Anderson, M. P. Fulscher, P. A. Malmqvist, L. Serrano-Andrés, K. Pierloot, and M. Merchán, Multiconfigurational Perturbation Theory: Applications in Electronic Spectroscopy, in: Advances in Chemical Physics: New Methods in Computational Quantum Mechanics, I. Prigogine, S. A. Rice (Eds.), John Wiley \& Sons, New York (1996).

42. S. F. Boys and F. Bernardi, Mol. Phys. 19 (1970) 553.

43. G. Chalasinski and M. M. Szczesniak, Chem. Rev. 94 (1994) 1723.

44. S. S. Xantheas, J. Chem. Phys. 104 (1996) 8821.

45. G. Lendvay and I. Mayer, Chem. Phys. Lett. 297 (1998) 365.

46. D. L. Singleton and R. J. Cvetanovic, J. Am. Chem. Soc. 98 (1976) 6812.

47. H. Eyring, J. Chem. Phys. 3 (1935) 107.

48. H. S. Johnston, Gas Phase Reaction Rate Theory, Roland Press Co., New York (1966).

49. K. J. Laidler, Theories of Chemical Reaction Rates, McGraw-Hill, New York (1969).

50. C. Eckart, Phys. Rev. 35 (1930) 1303.

51. A. Miyoshi, GPOP software, revision 2013.07.15m6, http://www.frad.t.u-tokyo.ac.jp/ $\sim$ miyoshi/gpop/ (2014).

52. S. W. Benson, O. Dobis, and A. C. Gonzalez, J. Phys. Chem. 95 (1991) 8423.

53. D. B. Hartley and S. W. Benson, J. Chem. Phys. 39 (1963) 132.

54. N. Leplat, Unpublished observations (2015).

55. L. M. Avallone, J. Photoch. Photobio. A 157 (2003) 231.

56. A. Mellouki, R. K. Talukdar, and C. J. Howard, J. Geophys. Res.-Atmos. 99 (1994) 22949.

57. Y. Bedjanian, V. Riffault, and G. Le Bras, Int. J. Chem. Kinet. 33 (2001) 587.

58. A. Vipond, C. E. Canosa-Mas, M. L. Flugge, D. J. Gray, D. E. Shallcross, D. Shah, and R. P. Wayne, Phys. Chem. Chem. Phys. 4 (2002) 3648.

59. S. Dobé, F. Temps, T. Bohland, and H. G. Wagner, Z. Naturforsch. A 40 (1985) 1289.

60. D. M. Golden, K. Y. Choo, M. J. Perona, and L. W. Piskiewicz, Int. J. Chem. Kinet. 8 (1976) 381. 
61. O. Dobis and S. W. Benson, J. Am. Chem. Soc. 113 (1991) 6377.

62. D. G. Truhlar and B. Garret, Annu. Rev. Phys. Chem. 35 (1984) 159.

63. J. H. Knox and R. H. Musgrave, T. Faraday Soc. 63 (1967) 2201.

64. J. Ree, Y. H. Kim, and H. K. Shin, J. Korean Chem. Soc. 34 (2013) 2473.

65. T. F. Hunter and K. S. Kristiansson, J. Chem. Soc. Faraday T. 78 (1982) 2067.

66. D. M. Hayes and R. L. Strong, J. Phys. Chem. 90 (1986) 6305.

Supplementary material: The online version of this article (DOI: 10.1515/zpch-2015-0607) provides supplementary material for authorized users. 